\title{
TARI SEKURA SEBAGAI MEDIA PELESTARI TOPENG SEKURA DARI LIWA LAMPUNG BARAT
}

\author{
Ahmad Susantri \\ Program Pascasarjana, Institut Seni Indonesia Yogyakarta \\ Email: ahmadsusantri30@gmail.com
}

RINGKASAN

Tulisan ini membahas usaha pelestarian kebudayaan yang dimediasi oleh sebuah karya seni tari yang muncul dari kebudayaan itu sendiri. Topeng sekura sebagai produk kebudayaan dalam rangkaian acara adat Pesta Sekura Cakak Buah menjadi lebih dikenal semenjak lahirnya tari Sekura. Proses kreatif penciptaan tari Sekura tidak hanya menghasilkan sebuah karya seni namun mendapatkan posisi yang lebih 'mulia' yaitu sebagai media promosi yang memperkenalkan topeng sekura ke berbagai tempat yang dulunya justru tidak mungkin untuk digapai. Tulisan ini tidak hanya memaparkan keberhasilan karya tari dalam melestarikan sebuah produk kebudayaan namun bagaimana perjalanan terbentuknya kebudayaan tersebut sehingga menjadi menarik untuk dilestarikan dan menjadi alasan mengapa harus dipromosikan.

Kata Kunci: Tari Sekura, Topeng Sekura, Liwa Lampung.

\section{ABSTRACT}

\section{SEKURA DANCE AS MEDIA OF SEKURA MASK PRESERVATION}

This paper discusses cultural preservation efforts mediated by a dance work which arises from the culture itself. Sekura mask as a cultural product in the series of traditional evebts pf the Sekura Cakak Buah festival has become more well known since Sekura dance was born. The creation creative process of Sekura dancedoes not only produse an art work but also obtain a more 'precious' position as a promotional medium which acquaints the Sekura mask into various places that previously are impossible to reach. This paper does not only elaborate the succes of dance works in preserving a cultural product but also how is the process of cultural formation it self becomes attractive to be preserved and becomes the reason why it should be promoted.

Keywords: Sekura Dance, Sekura Mask, Liwa Lampung. 


\section{PENDAHULUAN}

\section{Kecamatan Batu Brak kabupaten} Lampung Barat memiliki sebuah atraksi budaya yang dinamakan Pesta Sekura Cakak Buah, diselenggarakan pada tanggal 1 sampai 7 Syawal setiap tahunnya. Kesenian ini menjadi media silahturahmi dan perayaan setelah menjalani ibadah puasa di bulan Ramadhan. Pesta Sekura Cakak Buah merupakan kegiatan gotong royong masyarakat yang diwujudkan dalam acara panjat pinang, diselenggarakan oleh rakyat dan untuk rakyat. Pesta rakyat ini diisi dengan panjat pinang dengan buah pinang (hadiah) yang menarik. Terdapat pula penjual makanan tradisional dan beragam mainan anak-anak, rangkaian acara yang tumpah-ruah di perkampungan ini menjadi semakin semarak dengan kehadiran para sekura ${ }^{l}$. Para sekura menghibur masyarakat dengan tingkah laku yang lucu, berjualan bumbu dapur, sayur-mayur, dan perlengkapan rumah tangga lainnya. Setelah berjualan dan menghibur masyarakat sebagian dari mereka memanjat pohon pinang sebagai puncak acara Pesta Sekura Cakak Buah. Sekura mengenakan topeng yang kemudian juga disebut topeng sekura, bentuknya menyerupai bentuk abstrak dari

${ }^{1}$ Pelaku seni yang menggunakan topeng sekura disapa dengan panggilan sekura dan hanya dapat diperankan oleh para pria. wajah manusia yang dilebih-lebihkan rupanya sebagaimana yang biasa ditemukan pada topeng lainnya. Topeng selalu dihubungkan dengan wajah, maka bentuk dan perwujudan topeng selalu mewakili figur-figur tertentu, mimik atau ungkapan jiwa. $^{2}$ Sekura dibagi menjadi 2 kelompok, yang terdiri dari kelompok sekura yang memakai topeng dari pahatan kayu dan sekura yang menutup wajah dengan balutan kain.

1. Sekura Betik (Helau), penampilannya helau (indah), lucu, bersih dan sifatnya sebagai penghibur. Sekura betik menutup wajah dengan menggunakan kain panjang selindang miwang (kain khas masyarakat Lampung Barat), dan berkaca mata gelap. Di bagian pinggang dililitkan kain panjang yang menjuntai ke bawah. Banyak atau sedikitnya kain panjang yang dipakai oleh seorang atau kelompok orang yang sedang bersekura menunjukkan banyak atau sedikitnya muli (perempuan gadis) yang ikut dalam kebot-nya, ${ }^{3}$ karena kain panjang yang dipakai oleh sekura tersebut dahulunya adalah hasil pinjaman dari muli-muli yang ada

${ }^{2}$ Sumaryono, Antropologi Tari dalam Perspektif Indonesia, Yogyakarta: Media Kreativa Yogyakarta, 2017, p.97.

${ }^{3}$ Kebot merupakan bahasa daerah Lampung Sai Batin yang berarti kelompok masyarakat yang ruang lingkupnya tidak luas, seperti RW. 
dalam kebot adatnya. Sekura betik menghibur penonton dengan tingkah mereka yang bebas berekspresi. Sekura betik tidak berhak mengikuti panjat pinang dan hanya sebagai penggembira saja.

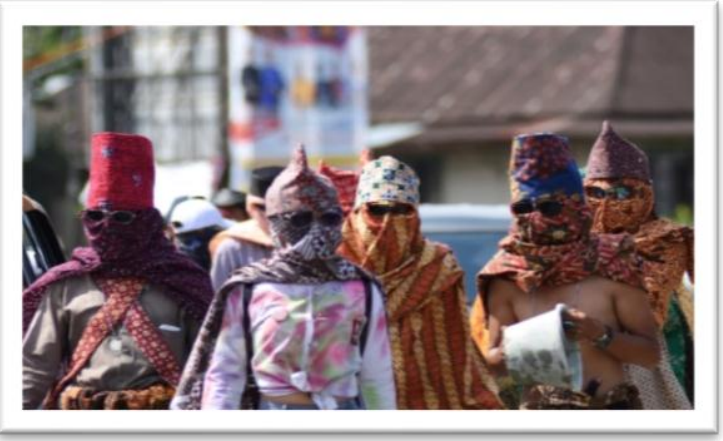

Gambar 1. Sekura Kecah (foto: Endang Guntoro, 2016, di Liwa)

2. Sekura Kamak (kotor), memiliki penampilan kotor, bisa disebut juga sebagai sekura calak. Sekura ini berciri khas kamak (kotor), memakai topeng dari bahan kayu atau dari bahan-bahan alami lainnya (tumbuhan). Bahan-bahan bekas menutupi tubuh mereka, menjadikan penampilannya lebih unik dan tampak kotor dengan pakaian yang dibentuk aneh namun terkesan lucu. Sekura kamak berhak memanjat pinang yang telah ditentukan. Para sekura kamak yang tergabung dalam kebotnya bersaing dan bekerjasama untuk mencapai puncak pinang dan menjadi pemenang.

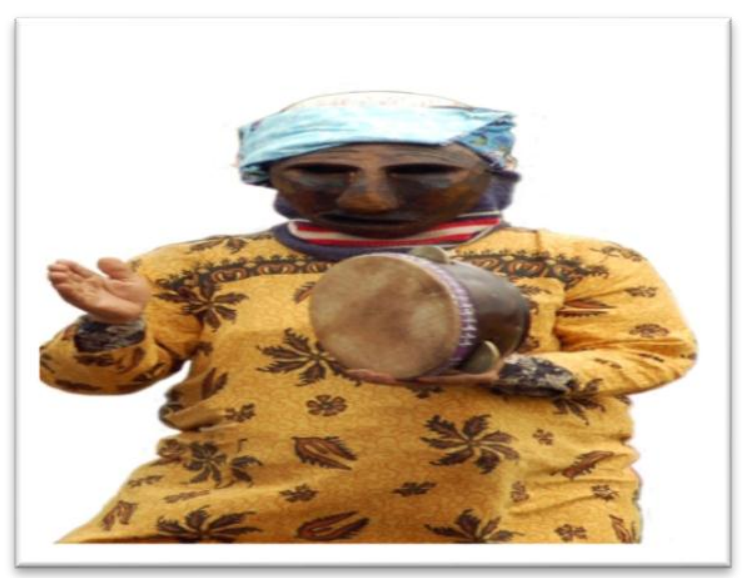

Gambar 2. Sekura Kamak foto: Endang Guntoro, 2016, di Liwa)

Kehadiran sekura menjadi daya tarik tersendiri dalam acara ini, tingkah laku dan penampilan nyentrik mereka menjadi sebuah daya pikat. Kemampuan mereka untuk membaur serta menghibur menjadi sebuah pemandangan estetis, seakan-akan mereka sedang melakukan pertunjukan tanpa menggunakan konsep yang pasti, murni untuk menghibur dan bergembira dengan masyarakat yang turut dalam Pesta Sekura Cakak Buah. Sayangnya sekura hanya dapat disaksikan pada tanggal 1 sampai7 Syawal setelah umat Islam merayakan hari raya Idul Fitri. Tidak semua masyarakat dapat menyaksikan acara menarik ini dikarenakan waktu pelaksanaan yang terikat dengan acara hari raya Idul Fitri saja.

Hal inilah yang memicu Edwarsyah Ma'as seorang seniman tari Lampung Barat untuk menciptakan Tari Sekura. Terinspirasi dari tingkah laku dan tata 
busana sekura, pada tahun 1990 ia menciptakan tari Sekura. Ia berharap agar kesenian ini mendapatkan posisi di hati masyarakat dan dapat dijumpai di berbagai waktu sehingga sebuah produk budaya yang menarik ini dapat diakses oleh masyarakat luas. Media ini menjadi sangat tepat sasaran sebagai bentuk kesenian praktis berupa pertunjukan tari untuk mengenalkan topeng sekura ke wilayah yang lebih luas. Melalui tari Sekura, pelaku seni tari dapat menghadirkan topeng sekura yang merupakan bagian terpenting dalam Pesta Sekura Cakak Buah. Setidaknya penonton mendapat gambaran tentang sekura yang menjadi elemen utama dalam Pesta Sekura Cakak Buah. Edwarsyah Ma'as mengatakan:

"Tradisi Sekura merupakan acara
tradisional kerakyatan yang biasa
diselenggarakan dalam merayakan hari raya
Idul Fitri untuk mengungkapkan rasa
syukur, suka cita, dan perenungan terhadap
sikap dan tingkah laku. Tari Sekura ini
diangkat dari tradisi masyarakat Lampung
Barat setiap awal bulan Syawal yang
berlangsung tiga sampai tujuh hari ini, yaitu
Pesta Sekura Cakak Buah. Awal mulanya
tari ini digarap dengan harapan supaya
tradisi sekura tetap lestari"

Pada akhir abad 20 tari Sekura menjadi alternatif perjumpaan dengan topeng sekura karena tari ini dapat ditemukan pada beberapa event yang diselenggarakan oleh pemerintah daerah ataupun perseorangan yang menanggap tari ini. Tercatat produksi tari secara besar-besaran dilaksanakan pada pementasan tari Sekura pada Pesta Kesenian Bali tahun 2003 yang dilengkapi dengan workhsop tari Sekura. Pada tahun 2005 tari Sekura dipertunjukan di Tunjungan Plaza Surabaya. Pada tahun 2006 tari Sekura dipertunjukkan di berbagai kota, yaitu di Surakarta untuk memeriahkan acara 24 Jam Menari, Festival Musik Tradisional di Bengkulu, dan Dhamashanti di Palembang. Pada tahun 2011 Tari Sekura dipentaskan secara massal pada acara closing ceremony MTQ Provinsi Lampung, dan pada tahun 2014 dengan tema "Sekura" Lampung Barat mendapatkan penganugrahan 6 karya terbaik di Tapis Karnival. ${ }^{4}$

Kehadiran tari Sekura pada penghujung abad ke-20 menjadi angin segar untuk media pelestari dan promosi topeng sekura. Dalam wujud tari, sekura menjadi lebih fleksibel untuk dipentaskan di manapun dan kapanpun. Hal ini menjadi daya pikat dan media untuk mempromosikan Lampung Barat. Hal ini dibuktikan dengan mulai berdatangan wisatawan domestik maupun mancanegara ke Lampung Barat pada setiap Pesta Sekura Cakak Buah yang diselenggarakan setiap tahunnya pada awal bulan Syawal.

\footnotetext{
${ }^{4}$ Wawancara dengan Nyoman Mulyawan, seniman Lampung Barat, yang telah berpuluh tahun menjabat sebagai ketua sanggar seni SETIWANG PEMDA Lampung Barat.
} 
JOGED

ISSN: 1858-3989

Keberadaan tari Sekura menjadi sebuah jawaban atas peran kesenian dalam melestarikan kebudayaan. Sebuah kebudayaan yang pada awalnya hanya menjadi bagian dari sekelompok masyarakat menjadi pertunjukan yang mudah untuk diakses oleh masyarakat luas. Sekura yang menjadi elemen penting pada Pesta Sekura Cakak Buah mengalami perubahan dari sebuah performance art berbasis kesenian tradisi yang hadir dan dibawakan oleh masyarakat lokal menjadi sebuah performing art yang dapat dilakukan oleh siapa saja yang mempelajarinya.

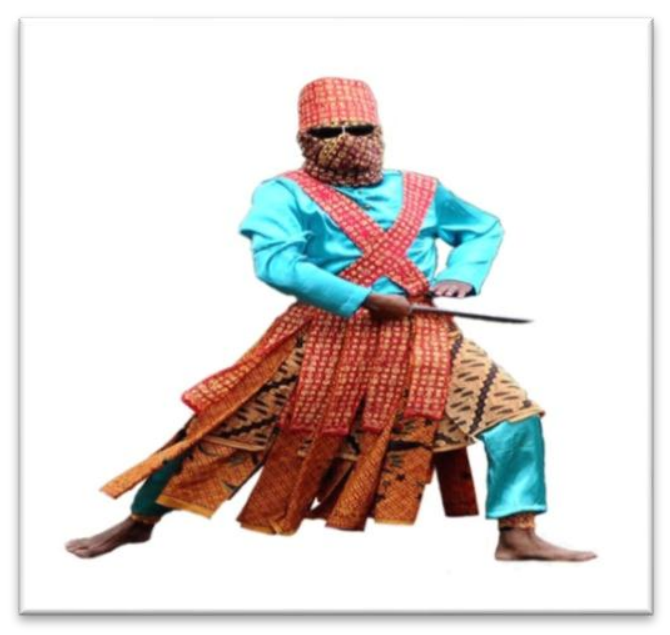

Gambar 3. Penari Sekura dengan kostum pentas (foto: Endang Guntoro, 2016, di Liwa)

Kehadiran Tari Sekura sebagai respons Edwarsyah Ma'as terhadap sekura menjadi hal yang menarik. Sebuah karya seni tari yang terlahir dari kegelisahan koreografer terhadap citra kebudayaan lokal untuk dapat dipromosikan ke ruang lainnya bertujuan agar masyarakat penonton yang
Ahmad Susantri I TARI SEKURA SEBAGAI MEDIA TOPENG SEKURA DARI LIWA LAMPUNG BARAT

mengetahui kebudayaan ini semakin luas. Namun, apakah karya Tari Sekura sudah cukup mewakili makna dari topeng sekura, sehingga keberhasilan tari Sekura menjadi salah satu media dalam melestarikan keberadaan sekura ini diikutsertakan dengan edukasi tentang topeng sekura? Apakah hanya sebagai mediator untuk memberikan informasi keberadaan Pesta Sekura Cakak Buah sebagai sebuah eksploitasi kebudayaan agar dapat dikonsumsi sebagai produk wisata. Bukankah sebuah karya seni apalagi yang terinspirasi dari sebuah kebudayaan lokal memiliki tanggung jawab untuk merawat dan melestarikan keutuhan budaya tersebut, keduanya tidak dapat dipisahkan terutama yang berawal dari sebuah tradisi yang telah mengakar. Maka selanjutnya dibahas asal muasal hadirnya topeng sekura dalam Pesta Sekura Cakak Buah dan bagaimana tari Sekura memposisikan dirinya sebagai pelestari, sebuah seni tari yang mengemban tugas khusus sebagi media promosi dan eksistensi sebuah masyarakat.

\section{PEMBAHASAN}

Lampung Barat merupakan daerah di mana Pesta Sekura Cakak Buah tumbuh dan berkembang serta merupakan wilayah yang menjadi pusat kerajaan pertama di Provinsi 
Lampung. Menurut catatan sejarah, kerajaan pertama di Lampung berasal dari kerajaan Sekala Brak yang berada di Lampung Barat. Dalam tambo yang menjadi pijakan sejarah kerajaan ini, tertulis raja pertama Sekala Brak adalah La Laula yang memerintah pada Tarikh 9 Margasira 919 Saka, sayang tambo tersebut tidak menyebutkan secara runtut siapakah raja-raja selanjutnya. Yang tertera, hanyalah Sangkan (12M), Mucca Bawo (12-13M), dan Sekeghumong (13M) yang tercatat sebagai raja-raja yang memerintah kerajaan Hindu-Animisme yang dikemudian hari menjadi kerajaan Islam.

Pada era Sangkan berkuasa, kerajaan ini memiliki nujum (ramalan) yang mengatakan bahwa akhir dari kedaulatan kerajaan Sekala Brak Hindu-Animisme akan jatuh saat masa kekuasaan Sekeghumong, seorang wanita cantik anak dari putra Sangkan yang dikemudian hari menjadi pewaris tahta kerajaan Sekala Brak. Hal ini tentunya menjadi momok yang menakutkan dalam masa pemerintahan Sekeghumong. Dari novel Perempuan Penunggang Harimau karya M. Harya Ramdhoni Julizarsyah $^{5}$ yang merupakan karya fiksi dengan sumber cerita realis, didapatkan

\footnotetext{
${ }^{5}$ Seorang sastrawan Lampung di tahun 2018 mendapatkan penghargaan SASTRA RANCAGE, juga merupakan keturunan Kesultanan Sekala Brak Paksi Pak Marga Liwa dengan gelar Suttan Pageran Indrapati Cakranegara VII.
}

gambaran betapa bengisnya ratu ini menggunakan tahtanya sebagai penguasa Sekala Brak kuno. Peraturan yang kemudian menjadi ritual adat istiadat diselenggarakan secara keji, pemenggalan kepala dara tercantik ataupun pemuda tertampan sebagai penghormatan kepada dewa dan dewi menjadi salah satu bentuk cara Sekeghumong agar nujum itu dapat ditentang oleh kuasanya dengan restu dewata. Sampai pada akhirnya pertanda runtuhnya kerajaan ini mulai terendus saat dua maulana yang dikemudian hari diketahui dari Peureulak yaitu Maulana Imam Al Hasyir dan anaknya Maulana Nyerupa berhasil meracuni suami Sekeghumong hinga tewas.

Pada tahun selanjutnya maulana $\mathrm{Al}$ Hasyir bersama keempat anaknya datang kembali ke tanah Sekala Brak, kali ini turut hadir maulana Belunguh, maulana Pernong, maulana Bejalan Diway yang merupakan saudara dari maulana Nyerupa. Mereka datang ke Sekala Brak untuk menyebarkan agama Islam. Walaupun yang tertulis di batu Pagaruyung yang bertahun $1358 \mathrm{M}$ ada empat orang raja dari Pagaruyung yang menyebarkan agama Islam di Lampung, dapat diindikasikan sebelum menjadi bagian dari kerajaan Pagaruyung empat maulana beserta ayahandanya berasal dari Peureulak. Cara penyebaran Islam bukanlah seperti 
para pedagang Islam kebanyakan yang berdakwah dengan cara pendekatan kebudayaan seperti para Wali Songo di tanah Jawa yang berhasil merenggut hati masyarakat setempat dengan dakwah melalui kesenian. Sistem penyebaran agama Islam oleh mereka hampir sama dengan cara berdakwah para penyebar Islam dari Peureulak. Salah satu ciri penyebaran agama Islam para pendakwah Peureulak adalah dengan cara berperang

Kedatangan empat maulana untuk menyebarkan agama Islam disambut dengan baik oleh sebagian keturunan suku tumi ${ }^{6}$ kerajaan Sekala Brak namun tidak sedikit yang menentang ajaran ini, terutama Ratu Sekeghumong yang sama sekali tidak mengizinkan Melasa Kepampang yang merupakan sesembahan agung penghubung antara hamba sahaya dengan para dewata dibabat habis oleh empat Maulana. Sebagai bentuk perlawanan terjadi peperangan, termasuk perang sesama suku tumi. Demi untuk menghilangkan rasa kasihan antar sesama suku, dikenakanlah topeng yang terbuat dari kikisan kayu sebagai penutup wajah saat perang berlangsung. Topeng

${ }^{6} \mathrm{Suku}$ tumi adalah keturunan imigras bangsa-bangsa purba dari Hindia Belakang pada tahun 2000 SM. Para sejarawan menyebut mereka sebagai Proto Melayu atau Melayu Pertama. Sekitar tahun 2000 SM nenek moyang bangsa Austronesia datang ke Indonesia melalui daerah Teluk Tonkin. Mereka membawa kebudayaan batu neolithikum yang disebarkan melalui jalur utara dan selatan. inilah yang disebut sebagai topeng sekura. Keduanya, dari pihak yang telah menganut agama Islam maupun para militan tentara dan rakyat kerajaan Sekala Brak yang masih menganut Hindu-Animisme memakai topeng untuk menutupi identitas diri dalam berperang.

Tidak ada keterangan jelas seberapa lama peperangan ini terjadi namun dari tahun yang disebutkan dalam batu Pagaruyung, agama Islam masuk ke kerajaaan Sekala Brak pada abad ke 14 M. Setelah perang dimenangkan oleh keempat maulana maka dibentuklah kerajaan Paksi Pak Sekala Brak yang merupakan kerajaan federasi dengan empat raja dalam satu negara/kerajaan. Masing-masing memiliki daerah kekuasaannya masing-masing tanpa mengkakak-adikkan satu sama lainnya, sama-sama berdaulat, dan memiliki hak yang sama.

Setelah peperangan usai topeng sekura berubah fungsi sebagai media untuk bersilahturahmi. Sebagai kerajaan bercorak Islam yang menang dari dakwah dengan cara berperang, segala bentuk adat dan kebudayaan yang sifatnya bertentangan dengan agama Islam ditiadakan, segala ritual yang sifatnya syirik dibumihanguskan. Salah satu kebudayaan yang tetap lestari dan bercorak Islam adalah perayaan syawalan 
yang diselenggarakan pada tanggal 1 sampai dengan 7 Syawal sebagai upacara silahturahmi antar warga pekon (desa). Acara ini dinamai Pesta Sekura Cakak Buah di mana topeng sekura tidak lagi menjadi simbol peperangan melainkan menjadi sebuah properti yang dipakai oleh para pelaku yang terlibat dalam acara ini.

Topeng sekura dalam acara ini menjadi bagian utama, di mana para sekura menghibur warga yang berhamburan di lokasi Pesta Sekura Cakak Buah, para sekura bergerak bebas diiringi oleh musik sederhana dari terbangan dan gong yang dibawa sambil berjalan kaki. Ada pula sekura yang berjualan. Pada puncak acara sekura kamak memanjat pinang dan membagikannya dengan warga.

\section{Pada perkembangannya sekura} dibagi menjadi dua kelompok, sekura betik dan sekura kamak. Sekura betik menjadi bagian dari sekura yang terlihat rapih dan berdandan dinamis, menggunakan tutup kepala yang terbuat dari kain dengan menggunakan kacamata. Pakaiannya pun terlihat rapih dengan juntaian kain selindang miwang yang menambah estetika penampilan sehingga terlihat lebih rapih dan gagah, sedangkan sekura kamak memakai topeng yang terbuat dari kayu yang telah diukir atau bahan-bahan yang berasal dari lingkungan lainnya. Pakaian yang digunakan sangat bebas, menjadikan penampilan mereka terlihat jenaka dan menghibur. Dalam pengamatan dan hasil wawancara dengan Novan Adi Putra ${ }^{7}$ di tahun 2014, pengelompokkan ini bersinggungan dengan makna dari Lebaran itu sendiri di mana terdapat kebaikan dan keburukan sebagai sifat manusia, sifat kebaikan diwakili oleh penampilan sekura betik dan sifat keburukan diwakili oleh sekura kamak.

Dalam pelaksanaannya tidak ada perbedaan yang signifikan dari pembedaan kedua golongan ini dari masyarakat. Keduanya melebur dan sama-sama menghibur masyarakat hanya saja sekura kamak menjadi satu-satunya sekura yang diperbolehkan untuk memanjat pinang. Penampilan sekura yang jenaka tampaknya dikagumi oleh banyak kalangan, termasuk saya yang secara pribadi mengalami perjumpaan dengan para sekura.

Dari urain di atas dapat diketahui penggunaan topeng sekura pada awalnya diperuntukkan bagi para prajurit dari kedua belah pihak yang bersiteru untuk berperang. Tujuannya untuk menghilangkan rasa iba

${ }^{7}$ Pemerhati budaya Lampung Barat, 29 tahun. Aktif dalam menulis dan mengkaji kebudayaan dan asat istiadat Lampung Barat. Bekerja di Anjungan Provinsi Lampung Taman Mini Indonesia Indah. 
dari perang saudara saat Islam masuk ke kerajaan Sekala Brak yang cara dakwahnya dilakukan dengan berperang. Setelah Islam menjadi pemenang, topeng sekura tidak langsung hilang, kegunaannya dialihfungsikan menjadi sebuah perangkat kebudayaan dalam Pesta Sekura Cakak Buah.

Topeng sekura menjadi simbol silahturahmi bagi masyarakat Lampung Barat. Penempatannya di era sekarang dalam rangkaian syawalan menjadi penegas hal tersebut. lalu bagaimana makna tari sekura yang tersampaikan ?. Selama tiga tahun menjadi participant observer, yang mempelajari dan juga menari Sekura, secara tidak langsung dapat menganalisis karya ini. Dalam setahun tarian ini dapat dipentaskan lebih dari 6 kali, terhitung dari tahun 2009 sampai 2012 saya aktif mengulang pembelajarn tentang tari Sekura dan mementaskan secara rutin tarian tersebut dalam beberapa acara di dalam dan luar kota. Tarian dengan durasi 7 menit ini ditarikan secara kelompok. Sebagai tarian large group compotition tarian ini biasanya dibawakan lebih dari lima penari. Pada awalnya tari Sekura hanya dilakukan oleh pria, namun sekarang banyak wanita yang turut menarikan tari ini. Menggunakan topeng yang terbuat dari kain serta menggunakan kaca mata, kain yang menjuntai dari bagian pinggang dan busana kurung berwarna cerah, sekilas tari Sekura secara terang-terangan mengadopsi busana yang dikenakan oleh Sekura Betik hanya saja distilisasi agar tampak indah di atas panggung.

Tidak ada motivasi khusus dalam membawakan tari ini, gerak yang dilakukan bernuansa ceria. Tempo tarian pun stabil dengan ritme gerak yang cepat, secara tidak langsung suasana penari terkesan ceria dengan gerak yang diadopsi dari gerak silat. Beberapa pola gerak disusun seperti menyajikan kesan kebersamaan seperti pola melingkar dan memegang kain yang menjuntai dari kostum yang dikenakan penari, membentuk barisan lurus dan lingkaran, ada kesan kebersamaan yang ditampilkan dalam tarian ini. Pola gerak jenaka ditampilkan saat beberapa adegan didramatisir seperti kejadian tidak disengaja seperti penari satu menabrak penari lainnnya hingga terjatuh, biasanya penonton akan tertawa melihat aksi ini. Menuju akhir tarian, penari menggunakan properti pedang yang terbuat dari kayu. Belum ditemukan alasan yang jelas kenapa memakai properti pedang. Tampaknya hal ini mengadopsi beberapa Sekura betik saat Pesta Sekura Cakak Buah yang memang membawa pedang, atau mungkin menyimbolkan sisi kepahlawanan bagi pihak tertentu yang 
melekat saat kemunculan topeng Sekura ini sendiri.

Dari menonton dan menjadi pelaku tari Sekura, dapat disimpulkan tidak ada ekspresi peperangan yang tergambarkan dalam tari ini. Tari Sekura tidak membawa tema peperangan antar saudara dalam tampilannya, hanya sekedar terinspirasi dari keberadaan Sekura yang telah menjadi media silahturahmi dalam ragkaian acara Pesta Sekura Cakak Buah. Sejarah kelam muasal topeng sekura tampaknya tidak dipilih sebagai ilustrasi dalam penyajian karya tari ini. Tampilan gembira dan enerjik menjadi pilihan koreografer dalam menciptakan karya ini. Dengan kostum yang tampak ramai menjadikan penampilan karya ini semakin menghibur. Sebuah tema yang pas untuk dipilih bila tujuan yang diinginkan koreografer menjadikan karyanya sebagai karya komersial. Ketertarikan khalayak terhadap tarian ini menjadi semakin besar saat tarian ini ditarikan dengan jumlah penari yang banyak lebih dari 10 bahkan mencapai ratusan penari. Gerak yang enerjik dan kostum yang ramai benar-benar berhasil memanjakan mata penonton. Tak pelak karya ini beberapa kali menjadi suguhan pertunjukan andalan kabupaten Lampung Barat dalam berbagai acara skala regional maupun nasional. Dari sini nama Sekura semakin dikenal orang, ketertaikan tersebut membawa rasa penasaran masyarakat luas dari dalam dan luar provinsi Lampung untuk melihat Sekura di 'kandangnya' sendiri. Sejak tahun 2008, festival-festival yang diadakan di Lampung Barat banyak menampilkan Sekura sebagai brand yang ditawarkan kepada para pengunjung festival. Tidak hanya itu Pesta Sekura Cakak Buah kini mulai dihadiri wisatawan domestik dan manca negara. Apresiasi terhadap sekura menjadi momentum bagi pemerintahan kabupaten Lampung Barat untuk melegalkan identitas kebudayaan ini dengan prestasi. Pada tahun 2016 arak-arakan Sekura dengan jumlah 5.454 orang menggunakan topeng sekura dihadiahi MURI sebagai rekor arakan topeng Sekura terbanyak di Indonesia. Bahkan di tahun 2017 patung Sekura telah dibangun di jantung Ibu kota Liwa sebagai tanda kecintaan masyarakat terhadap topeng sekura ini. 


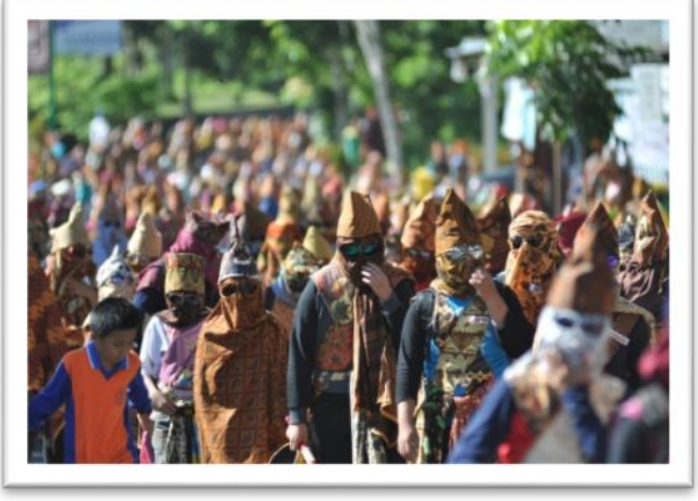

Gambar 4. Pemecahan Rekor MURI sekura terbanyak (foto: Endang Guntoro, 2017, di Liwa)

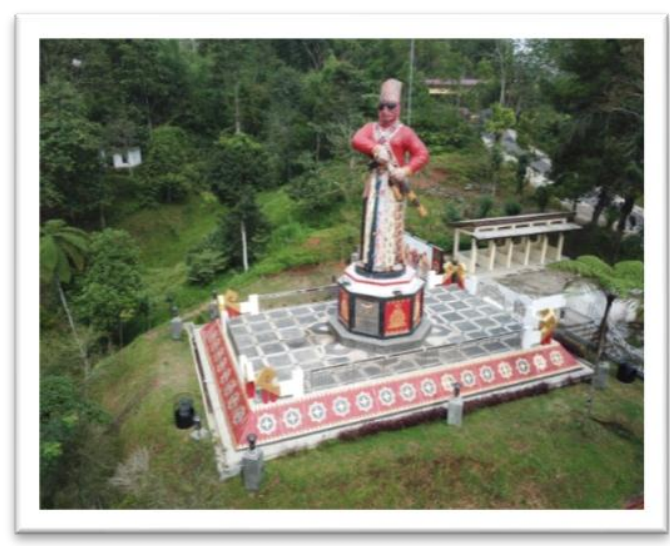

Gambar 5. Tugu Sekura berdiri kokoh di jantung kota Liwa (foto: Endang Guntoro, 2018, di Liwa)

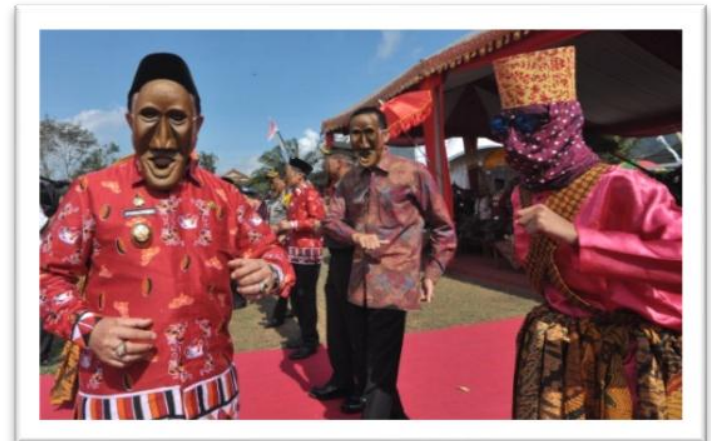

Gambar 6. Penari sekura membaur dengan tamu undangan di salah satu acara daerah (foto: Endang Guntoro, 2015, di Liwa)

\section{PENUTUP}

Keberadaan tari Sekura menjadi angin segar terhadap kelestarian dan eksistensi topeng Sekura. Berkat tari Sekura banyak orang yang dapat mengenal bentuk topeng Sekura. Sajian pertunjukan tari ini memudahkan penyebaran informatif tentang keberadaan topeng Sekura. Tema yang diangkat dalam tari Sekura dirasa sesuai dengan tujuan penciptaan tarian ini, sebuah karya komersil yang bersifat entertainer yang mengedepankan informasi menarik tentang produk yang diusung sebagai ide penciptaan karya. Susunan koreografi yang berhasil menarik perhatian sehingga dengan lugas karya tari ini menjadi media pelestari sebuah kebudayaan. Ada banyak contoh dewasa ini tarian yang mengangkat obyek tradisi ke dalam garapannya, namun tidak semua koreografer dapat dengan pas menentukan tema sehingga karya yang dibuat menjadi sebuah perpanjangan cara untuk mengenalkan tradisi/budaya yang diusung. Tari Sekura mampu untuk menyebarluaskan informasi tentang Pesta Sekura Cakak Buah dan ikut melestarikannya.

\section{DAFTAR SUMBER ACUAN}

\section{A. Sumber Tertulis}

Hadi, Y. Sumandiyo. 2017. Koreografi Bentuk-Teknik-Isi. Yogyakarta: Cipta Media..

Hawkins, Alma M. 1998. Creating Through Dance, New Jersey: Princeton 
Book Company. Diterkjemahkan

oleh Sal Murgiyanto, 1997.

Pedoman Dasar Penata Tari,

Jakarta: Lembaga Pendidikan

Kesenian Jakarta.

Marianto, M. Dwi. 2017. Art \& Life Force in a Quantum Perspective. Yogyakarta: Scitto Books publisher

Martono Martono. 2008. Sekelumit Ruang Pentas Modern dan Tradisi. Yogyakarta: Cipta Media.

Murgiyanto, Sal. 2015. Pertunjukan Budaya dan Akal Sehat. Jakarta: Penerbit FSP-IKJ.

Simatupang, Lono. 2013. Pergelaran Sebuah Mozaik Penelitian Seni-Budaya. Yogyakarta: Jalasutra.

Nyoman Mulyawan, M.Sn

Peran : Guru tari penulis saat duduk dibangku SMA yang mengajarkan tari Sekura dan merupakan tokoh yang menglobalkan tari Sekura di berbagai acara.
Smith, Jacquelin. 1976. Dance Composition: A Practical Guide for Teachears. London: A \& Black. Diterjemahkan oleh Bne Suharto. 1985. Komposisi Tari: Sebuah Petunjuk Praktis Bagi Guru. Yogyakarta: Ikalasti.

Sumaryono, 2017. Antropologi Tari dalam Perspektif Indonesia. Yogyakarta: Media Kreativa Yogyakarta.

Yudiaryani, et.al. 2017. Karya Cipta Seni Pertunjukan. Yogyakarta: JB. PUBLISHER.

\section{B. Narasumber}

Edwarsyah Ma'as

Peran : Pencipta / koreografer tari Sekura

Alamat: Batu Brak, Lampung Barat. 


\section{JOGED}

ISSN: $1858-3989$
Ahmad Susantri I TARI SEKURA SEBAGAI MEDIA

PELESTARI TOPENG SEKURA DARI LIWA LAMPUNG BARAT

Nyoman Mulyawan, M.Sn

Peran : Guru tari penulis saat duduk dibangku SMA yang mengajarkan tari Sekura dan merupakan tokoh yang mengglobalkan tari Sekura di berbagai acara.

Alamat : Buleleng, Bali.

Novan Adi Putra (alm)

Peran : Pemuda pemerhati budaya yang telah mengarsipkan banyak tulisan tentang kerajaan Sekala Brak.

Alamat 